\title{
Multiplicative Thinking: 'Pseudo-procedures' are Enemies of Conceptual Understanding
}

\author{
Chris Hurst ${ }^{1^{*}}$, Derek Hurrell ${ }^{2}$ \\ ${ }^{1}$ School of Education, Curtin University, AUSTRALIA \\ ${ }^{2}$ University of Notre Dame Australia, AUSTRALIA \\ *CORRESPONDENCE: $\square$ c.hurst@curtin.edu.au
}

\begin{abstract}
Multiplicative thinking is widely accepted as a critically important 'big idea' of mathematics that underpins much mathematical understanding beyond the primary years. It is therefore important to ensure not only that children can think multiplicatively, but that they can do so at a conceptual rather than procedural level. This paper reports on a large study of 530 primary school children in Australia, New Zealand and the United Kingdom. The research question was "To what extent do children of 10 and 11 years of age understand what happens to digit values when numbers are multiplied and divided by powers of ten?" A written multiplicative thinking quiz was administered and one section of four questions asked students to multiply and divide two digit whole and decimal numbers by a power of ten and then explain what happened to the numbers. Correct response rates for the four calculations ranged from $38.3 \%$ to $61.7 \%$. Response rates for appropriate explanations about what happened to the numbers ranged from $2.6 \%$ to $5.5 \%$. Most students who attempted to explain what happened did so at a 'pseudo-procedural' level with responses such as 'a zero is added' or 'we take off the zero'. The students who did explain it conceptually did so in terms of the digits moving a place for each power of ten. The implication is that teaching of multiplication and division needs to be done at a conceptual level, with attention paid to the underlying mathematical structure, rather than relying on 'pseudoprocedures' such as 'adding a zero' which are unsustainable and will likely lead to errors.
\end{abstract}

Keywords: multiplicative thinking, procedures, conceptual understanding

\section{INTRODUCTION}

Multiplicative thinking has been identified as a critical set of ideas in the development of mathematical understanding (Siemon, Bleckley, \& Neal, 2012), underpinning important concepts related to algebraic reasoning, place value, proportional reasoning, ratios, and statistical sampling. (Siemon, Breed, Dole, Izard, \& Virgona, 2006). As well, Siegler et al. (2012) suggest that because multiplicative thinking supports understanding of division and fractions, it effectively determines the extent to which children progress beyond elementary mathematical knowledge, or otherwise. Skemp's formative (1976) paper drew attention to the importance of thinking and teaching for conceptual understanding. In addition, contemporary curricula highlight the importance of reasoning. The Australian Curriculum: Mathematics (ACARA, 2020) discusses Reasoning and Problem Solving as two of its Proficiency Strands and the Common Core State Standards for Mathematics (NGA Centre, 2010) emphasizes quantitative reasoning and 'the meaning of quantities' as important ideas. The study about which this article reports focused on the extent to which primary school children are able to reason mathematically and think beyond the use of procedures.

Article History: Received 2 June $2020 \bullet$ Revised 9 July $2020 \bullet$ Accepted 24 August 2020

(C) 2020 by the authors; licensee Modestum. Open Access terms of the Creative Commons Attribution 4.0 International License (http://creativecommons.org/licenses/by/4.0/) apply. The license permits unrestricted use, distribution, and reproduction in any medium, on the condition that users give exact credit to the original author(s) and the source, provide a link to the Creative Commons license, and indicate if they made any changes. 


\section{RELATED LITERATURE AND STUDIES}

\section{Relational and Instrumental Understanding}

Skemp's (1976) seminal paper about relational and instrumental understanding raised some important issues. He found it somewhat incongruous to equate 'instrumental' with 'understanding' as the former really is "rules without reasons" whereas relational understanding is "knowing both what to do and why" (Skemp, 1976, p. 89). In this paper, relational understanding is considered synonymous with "conceptual understanding' and 'connected knowledge' while instrumental knowledge is equated to 'procedural knowledge'. Skemp (1976, p. 92) also wrote how relational understanding "is more adaptable to new tasks". As an example of instrumental knowledge, he described how a student had learned a procedure for multiplying two decimals by removing and later replacing the decimal point. Apart from this practice being mathematically incorrect, Skemp noted that this it is deleterious as students inevitably try to apply it to other operations because they do not understand what is happening at a conceptual level. Later, we make the case for describing such things as 'moving the decimal point' as 'pseudo-procedures' as they are quite different to the use of genuine mathematical procedures. Teaching in a conceptual way for relational understanding is also preferred as ideas are seen as connected, cognitive load is reduced, and learning is more motivational. Skemp (1976) noted how good teaching illuminates the connections, and ideas from one concept are often transferred to the learning of another concept.

\section{Conceptual and Procedural Knowledge}

In their 2012 paper, Richland, Stigler and Holyoak raise the concern that many schools are not teaching a conceptual knowledge of mathematics, a knowledge which could support these students in their capacity to generalise and transfer that mathematics. This they suggest, is resulting in students, who in spite of successfully completing high school mathematics, are required to attend remedial mathematics courses when attending U.S. community colleges. Additionally, the research of Givvin, Stigler, and Thompson (2011) concluded that the mathematical knowledge of students entering community college was largely procedural, and left students with ineffective mathematical reasoning and in some cases conducting incorrect of partially correct procedures. This largely procedural knowledge becomes problematic, as that many of these community college students use their two-year associate degree as a stepping-stone to four-year degrees, which often require a more conceptual knowledge of mathematics (The Princeton Review, 2017).

If then, school systems such as in the US are producing students with ineffective reasoning and procedural approaches to solving mathematical problems, what sort of teaching and learning can be instituted to remedy this? This question only warrants attention if it is accepted that concentrating on the development of procedural knowledge is not the singular purpose of mathematics education, and that conceptual knowledge is also important. The importance of both types of knowledge is a position which seems universally accepted in research (Hiebert \& Grouws, 2007; Rittle-Johnson, Schneider \& Star, 2015) which allows the conversation to shift to determining the relationship between these two types of knowledge. This is a debate which is long standing (e.g. Resnick \& Ford, 1981; Sowder, 1998) and is still receiving attention today (Alcock et al., 2016; Rittle-Johnson, 2017; Rittle-Johnson \& Koedinger, 2009; Schneider, Rittle-Johnson, \& Star, 2011).

Conceptual knowledge can be defined as a linking web of relationships (Miller \& Hudson, 2007; RittleJohnson \& Schneider, 2015), where the linking can involve two previously learned mathematics ideas or concepts or linking previously learned concept with a newly learned concept (Rittle-Johnson, Fyfe, \& Loehr). It is considered by some researchers (e.g. Hiebert, 1986) as being knowledge which is rich in relationships and where the links in the relationship are at least as important as the discrete pieces of information that they link (Rittle-Johnson \& Schneider, 2015). This contrasts with Baroody, Feil, and Johnson (2007) who define conceptual knowledge as being knowledge about facts, generalisations and principles, but claim that there is no requirement for the knowledge to be richly connected. Rather their research, and the research of others (e.g. diSessa, Gillespie, \& Easterly, 2004; Schneider \& Stern, 2009) supports an idea that neophytes' conceptual knowledge can often be fragmented and can take time to become integrated and richly connected. Baroody, Feil, and Johnson's (2007) assertion may lead to developing an argument regarding not only the types of knowledge, conceptual being one, but also of qualities of that type.

Procedures are considered to be step-by-step action sequences to solve problems (Rittle-Johnson, 2017; Rittle-Johnson, Siegler, \& Alibali, 2001) or a series of actions and/or steps employed to achieve a goal or task (Hiebert \& Lefevre, 1986; Rittle-Johnson, Schneider, \& Star, 2015). These definitions, if taken without regard to the qualities of procedural knowledge, can lead to what Skemp (1976) refers to as learning rules without 
reason or understanding. Martin (2009) claims that the "mechanical execution of procedures" (p.165) can often lead to bizarre answers. Procedures can be algorithms (for example the formal written algorithm (sum) for adding two four-digit numbers together) or possible actions which are appropriately sequenced to solve a problem, for example steps for solving equations (Rittle-Johnson \& Schneider, 2015).

Procedural knowledge is the capacity to follow a sequential set of steps to solve a mathematical problem or goal (Canobi, 2009; Miller \& Hudson, 2007; Rittle-Johnson \& Schneider, 2015). This can involve a knowledge of, and familiarity with, the symbols system to write algorithms, but can also mean a knowledge of procedural rules for the solution of problems (Hiebert \& LeFevre, 1986; Rittle-Johnson \& Schneider, 2015). Many teachers may see procedural understanding to be devoid of relationships, a view not shared by researchers (Baroody, Feil, \& Johnson, 2007; Hiebert \& Wearne, 1986) who note that procedures are often interconnected with, and embedded within, other procedures. Again, it seems necessary to reflect on the qualities of knowledge rather than to just adopt a superficial and sometimes unconsidered, definition of this type of knowledge.

Pesek and Kirshner (2000) studied six fifth-grade U.S. mathematics classes, three of which were taught for half the study period using a procedural/instrumental approach, followed by teaching with a conceptual/relational approach. The other three classes were taught for the entire study period using a conceptual/relational approach. They found that students who were taught through a conceptual (or relational) approach outperformed students who were taught from a 'procedural first' (or instrumental) approach. Another issue with teaching procedures without understanding is that, once students know the procedure, they are usually reluctant to bother with learning the underpinning mathematical concepts (Hiebert, 1999; Puchner, Taylor, O’Donnell, \& Fick, 2010).

Other mathematics education researchers have written about this issue. Anthony and Walshaw (2009) noted that it is important for teaching to move beyond the use of procedural rules and that, as students are encouraged to make sense of the underlying mathematics through realising the connections between ideas, they become less focused on purely finding the answer and are more inclined to think about why certain processes work. Anthony and Walshaw (2009, p. 19) suggest that effective teachers ask students to "explain and justify their solutions [and] take and defend positions against the contrary mathematical claims of other students". Anthony and Walshaw (2002, p. 97) had noted earlier that "justification is central to mathematics" if students are to move beyond a procedural level of thinking. They found that students did not conceptually understand the commutative property and explained it in terms of 'switching' and 'swapping' the numbers. Similarly, Warren and English (2002, p. 625) argued that "the overriding emphasis on computational procedures at the expense of exploring relationships is largely responsible for children's limited understanding of arithmetic structure". Furthermore, Clements and Sarama (2019) recently discussed the importance of effective professional development for teachers based on the notion of learning trajectories. Indeed, they noted that, "As teachers come to understand children's probable developmental paths and become adept at anticipating children's strategies and misconceptions, their teaching practices may become more grounded and solidified" (Clements \& Sarama, 2019, p. 44). They appear to be alluding to, amongst other points, the importance of teachers seeing and understanding the mathematical connections in order for them to enable their students to do so.

In examining children's understanding in four case studies, Hurst (2018) found that two students who were deemed to be very capable mathematically and used procedures quickly and effectively were unable to explain how and why the procedures worked and could not use manipulatives such as bundling sticks to show what happened in a two digit by one digit multiplication example. Earlier, Hurst (2017) studied children's understanding of arrays, factor pairs, numbers of equal groups, the commutative property of multiplication, and the inverse relationship between multiplication and division, noting that most students had some knowledge of some of the structure but the overwhelming majority were unable to see how the ideas were connected. Recently, Downton, Russo, and Hopkins (2019) reported on a study of 25 students aged 11 and 12 years and their understanding of handling zeros in multi-digit multiplication. They found that the majority of students in the sample "have been taught the 'add zero' rule when multiplying decade numbers, but do not have an understanding of why the rule works" (Downton et al., 2019, p. 241). Most of the students talked of the 'magical zero', accepted it "as a fundamental rule [which they] did not challenge or question, even if they did not understand it" (Downton et al, 2019, p. 241). 


\section{Procedures or 'Pseudo-procedures' - What is the Difference?}

At this stage, it is important to distinguish what is meant by the term 'procedures' as there are two distinctly different things being referred to by the various researchers cited so far. First, there are legitimate mathematical procedures, and, as has been noted on several occasions, the learning of procedures is an important part of mathematical understanding. That is, children need to know how to use an algorithm for calculating answers to problems using the four operations when the magnitude of the numbers makes it too difficult to calculate mentally (Author \& Author, 2018a, 2018b). Also, 'formulae' for calculating quantities such as area, volume, and capacity (amongst other things) are useful for children to learn (Pesek \& Kirchner, 2000). Second, there are what could be called 'pseudo-procedures', which have no mathematical basis and are no more than 'mathematical tricks'. This group includes notions like 'adding a zero' and the 'magical zero' (Downton et al., 2019), and 'switches', and 'swap arounds' (Anthony \& Walshaw, 2002). It also includes the idea of 'moving the decimal point' (Skemp, 1976), all of which are examples of Skemp's (1976) 'rules without reasons'.

\section{Multiplicative Thinking}

The focus of this paper is regarding exploring the underlying structure of multiplicative ideas and the extent to which children are able to move beyond the use of 'pseudo-procedures' to a connected and conceptual understanding of the structure. Multiplicative thinking is a complex set of ideas that underpin most of the mathematics learned beyond the middle primary years. Indeed, Askew (2018) recently noted that secondary students' understanding of multiplicative reasoning was generally not strong which is likely to hamper development beyond an elementary level. The following definition, (Hurst, 2017) is based on the work of Siemon et al. (2006), and Siemon, Bleckley, and Neal (2012). Multiplicative thinking is demonstrated by an ability to

- Work flexibly with a wide range of numbers including very large and small whole numbers, decimals, fractions, ratio and percentage;

- Work conceptually with the relative magnitude of whole and decimal numbers in a range of representations, demonstrating an understanding of the notion of 'times as many';

- Demonstrate a conceptual understanding of the multiplicative situation, the relationship between multiplication and division, numbers of equal groups, factors and multiples, and the various properties of multiplication; and

- Articulate a conceptual understanding of a range of multiplicative ideas in a connected way with explicit language and terminology (Hurst, 2017, p. 1).

This paper is concerned with the second point in the definition focusing on what happens to the digits of a number when it is multiplied or divided by a power of ten, as well as the fourth point relating to children's ability to explain what happens. The capacity to understand this concept is built upon the base-ten property of place value, that is, that the values of the places increase in powers of ten from right to left (Ross, 2002). This gives rise to the understanding that if a digit of a number is moved one place from right to left, it becomes ten times bigger. If a digit is moved one place from left to right, it becomes ten times smaller. The capacity to understand, generate, and use extended number facts is also linked to this idea. That is, if one factor in a basic number fact such as $5 \times 7=35$ is increased by a power of ten, then the multiple (35) must also be increased by a power of ten. The theoretical framework for the study was developed from the connections between these ideas (Figure 1). 


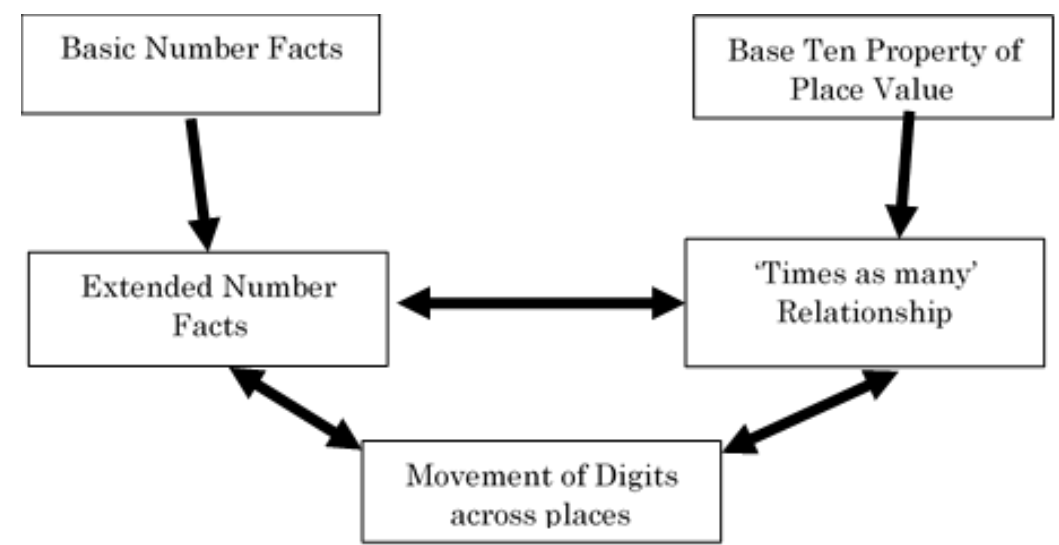

Figure 1. Theoretical framework for the study

Table 1. Responses to calculations for the four quiz questions

\begin{tabular}{ccc}
\hline Question & Frequency correct & Percentage correct \\
\hline $1.16 \times 10$ & 327 & 61.7 \\
\hline $2.160 \div 10$ & 268 & 50.6 \\
\hline $3.1 .6 \times 10$ & 203 & 38.3 \\
\hline $4.16 \div 10$ & 252 & 47.5 \\
\hline
\end{tabular}

\section{METHODOLOGY}

This paper reports on part of a larger study on children's multiplicative thinking, the overarching research question being, 'What level of conceptual understanding of multiplicative thinking, and multiplication and division is demonstrated by children aged 9 to 12 years in mainstream primary classrooms?' To attempt to answer an aspect of that overarching question, the following question reported on here was "To what extent do children of 10 and 11 years of age understand what happens to digit values when numbers are multiplied and divided by powers of ten?" A sample of 530 primary school students of ages ten and eleven years from Western Australia, New Zealand, and the United Kingdom was used for this study. A Multiplicative Thinking quiz was administered to the students as a whole-class exercise during the final stages of the school year for each jurisdiction. The quiz contained 18 questions on different aspects of multiplicative thinking. Only data generated from four of the quiz questions are considered here because those four questions were relevant to the specific research question. The quiz questions concerned are as follows:

1. Work out the answer to $16 \times 10$. Explain what happens when you multiply a number by 10 .

2 . Work out the answer to $160 \div 10$. Explain what happens when you divide a number by 10

3. What is the answer to $1.6 \times 10$ ? Explain or show how you did it.

4. Work out the answer to $16 \div 10$. Explain or show how you did it.

Responses to the questions were recorded on an Excel spreadsheet with a ' 1 ' for a correct or appropriate response and a ' 0 ' for an incorrect or inappropriate response.

\section{RESULTS AND DISCUSSION}

Responses to the four questions are considered in two parts. First is the response to the actual calculation part of each question and second is the explanation of what happened to the number and/or how the students worked it out. With regard to the calculations of correct answers, the results are shown in Table 1.

When considering the age of the students involved and the attention to multiplication that is stipulated in the curriculum documents, the results shown in Table 1 are lower than what could reasonably be expected. When breaking down the data to year levels, the proportion of correct responses for Question 1 ranged from $60.2 \%$ (Year 5) to $63.2 \%$ for Year 6. This pattern, that the Year 6 students performed better than the Year 5 students, was repeated for the other three questions with the difference being more accentuated with Questions 3 and 4. For Question 3, correct answers were given by $28.3 \%$ of Year 5 students, and $48.7 \%$ of Year 
Table 2. Summary of responses to the explanations for the four quiz questions

\begin{tabular}{ccc}
\hline Question & Frequency correct & Percentage correct \\
\hline $1.16 \times 10$ & 21 & 4.0 \\
\hline $2.160 \div 10$ & 14 & 2.6 \\
\hline $3.1 .6 \times 10$ & 29 & 5.5 \\
\hline $4.16 \div 10$ & 27 & 5.1 \\
\hline
\end{tabular}

6 students. For Question 4, the results were 42.8\% (Year 5), and 52.5\% (Year 6). While this is interesting, and a generally expected outcome that Year 6 students would do better than Year 5 students, it is not the main issue here. The main focus of the paper is not the capacity of the students to calculate (though this in itself is not trivial), it is the extent to which students can explain what occurred when the numbers were multiplied or divided by a power of ten.

Responses to the second part of each question, regarding explaining what was happening in the completion of the calculation, are summarised in Table 2. Responses were deemed to be appropriate/correct if they contained one of the following comments or something very similar:

- "I moved the digits" . . or . . "The digits moved one place"

- "It changed the place value"

- "I moved the digits and then added a zero"

- "It became ten times bigger/smaller" or "It became ten times as many"

Responses were deemed to be inappropriate if they contained one of the following comments or something very similar, with no further elaboration:

- "I added a zero ... I took away a zero"

- "I moved a zero"

- "I moved the decimal point"

These responses are described above as 'pseudo-procedures'

A telling observation to be drawn from Tables 1 and 2 is that while between $38.3 \%$ and $61.7 \%$ of the students were able to correctly calculate answers to the four questions, only $2.6 \%$ to $5.5 \%$ of the same students were able to explain what happened to the digits as a result of multiplication or division. No student gave an appropriate explanation while making an error in the calculation.

Although only a small percentage of students could explain in a conceptual way what happened to the digits, the explanations of those who did so were strong. Quinn said this: "When you multiply by ten, you move every number forward one space on the place value chart" [and] "When you divide, you do the opposite of multiplying by ten. You move every number backwards one place on the place value chart". Emma said something similar: "What happens is when you times a number by ten, it moves one place to the left". Elijah said that, [for $1.6 \times 10$ ] "Your number behind the decimal point moves one place to the left". Also, Brogan said, "I got it by moving everything one place to the right". Some students described it in different ways but still acknowledged that the digits moved to different places. Ali wrote, "If it is a two dightit [sic] number, it turns into the 100s. When it is a one dightit [sic] number, it turns into the tens". Pete also mentioned that when a number was multiplied, a zero is needed - "It gets ten times bigger so you add a place holder". Pete's use of the terminology alludes to him understanding that zero is needed as a place holder when the digits of a number are moved one place to the left. Charlie explained it in a similar way - "So you just move the numbers along to the left and add a zero".

Some students did a drawing to show a place value chart. Samples from Izzy, Cassie, and Freddie are included in Figure 2. 


\section{$1.6 \times 10=16$}

Explain or show how you did it.

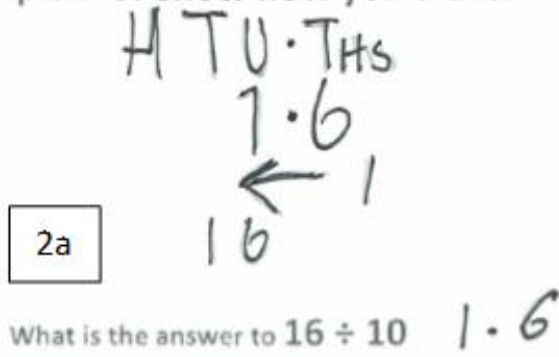

Please explain and/or show how you got your answer.

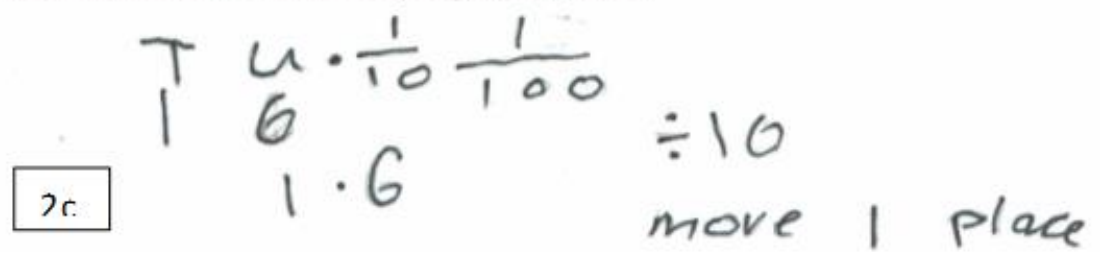

Figure 2. Samples from Izzy (2a), Cassie (2b), and Freddie (2c)

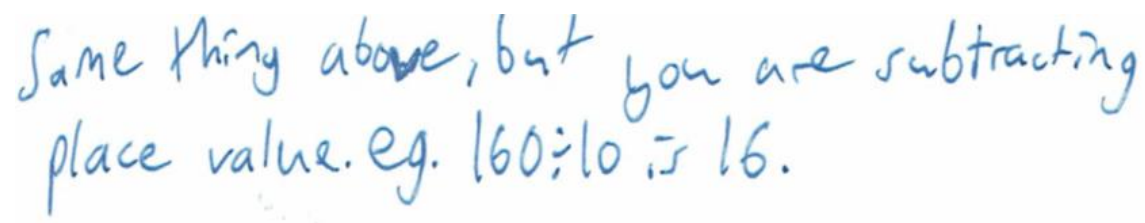

Figure 3. Sample from Adam

All of the samples above can be described as showing some conceptual understanding of the processes of multiplication and division. Of the 530 participant students, 49 provided a correct or appropriate explanation for at least one of the four questions. Only five of them did so for each of the four questions. It is interesting that most of the students who provided a strong conceptual explanation for one or more question reverted to a procedural response for another question. Two such students were Ryan and Andrew. Ryan said this - [For $16 \times 10$ ] . . "When you multiply a number by 10 you just add a zero to the other number and get your answer of 160". This is a procedural response and falls into Skemp's (1976) 'rules for reasons' category. However, Ryan then said - [For $16 \div 10$ ] . . "The answer is 1.6 . I had to divide by 10 which means my answer had to be in tenths so 1.6 would be the answer because if I went further, it would have been 0.16 ". Andrew responded in this way - [For $1.6 \times 10] \ldots$ "The answer is 16 - The decimal point goes down a place because the number's value increased". This is another example of a common procedural response, that of 'moving the decimal point'. Andrew responded quite differently for $16 \div 10$. He said, "The value decreases and since there is no other whole number, it has to go into decimals".

Some students demonstrated partial understanding or expressed their thinking in less elegant ways. For example, with regard to $16 \times 10$, Student Adam said, "Well, it always will change the place value of the number no matter what, e.g., $16 \times 10$ is 160 ". For $160 \div 10$, his response is shown in Figure 3 .

Another student, William, also gave a procedural answer followed by a conceptual answer. His second sample in Figure 4 contains some good terminology - 'the place holder chart' - suggesting that he may understand the importance of zero as a place holder. It is intriguing as to why these students and others in the sample talk about 'adding a zero' for one answer and then describe the movement of digits in the next answer. 
12. $16 \times 10 \neq 60$

- Explain what happens when you multiply a number by 10 (for example, $16 \times 10$ )

It just adds a Zero on the end

13. $160 \div 10=16$

- Explain what happens when you divide a number by 10. It moves I pace to the right on the place holder chart

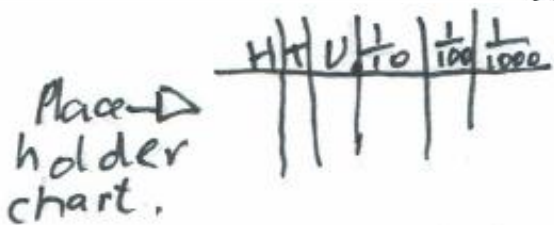

Figure 4. Samples from William

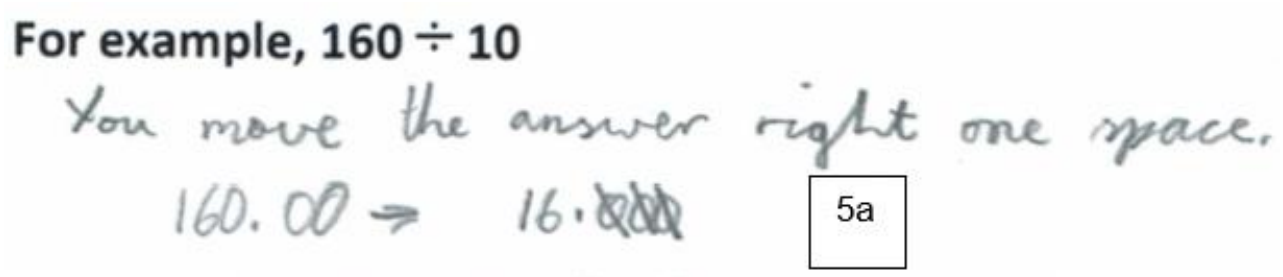

What is the answer to $16 \div 10$

Please explain and/or show how you got your answer.
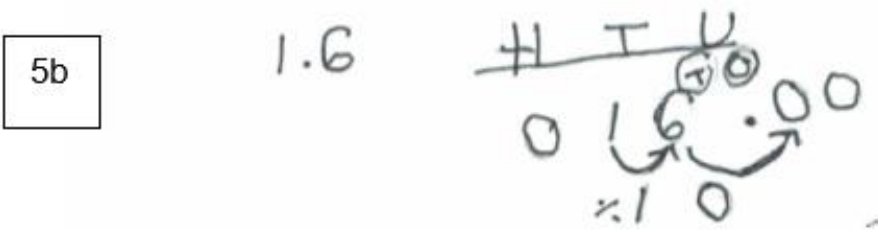

Figure 5. Sample from Flynn (5a) and Jess (5b)

As well, other students acknowledged that the digits moved to a different place when the number was multiplied or divided but persisted with the notion of 'adding a zero' or 'taking off a zero'. This also shows partial or developing understanding. James wrote that [for $160 \div 10$ ], "It looses [sic] a zero so it goes one place to the right" and Chris said [for $16 \times 10$ ], "It's simple, you just add a zero on the end which makes the other numbers move up in place value". The earlier cited examples from Pete and Charlie are conceptually stronger because they talk about moving the digits to a different place and the zero being added as a place holder. Responses from Flynn [for $160 \div 10$ ] and Jess [for $16 \div 10$ ] imply that they have developed some understanding of zero as a place holder as they have shown empty places as being filled with a zero.

Ollie was the only student to use a vertical algorithm to multiply 1.6 by 10 and he also showed the movement of digits by one place. 


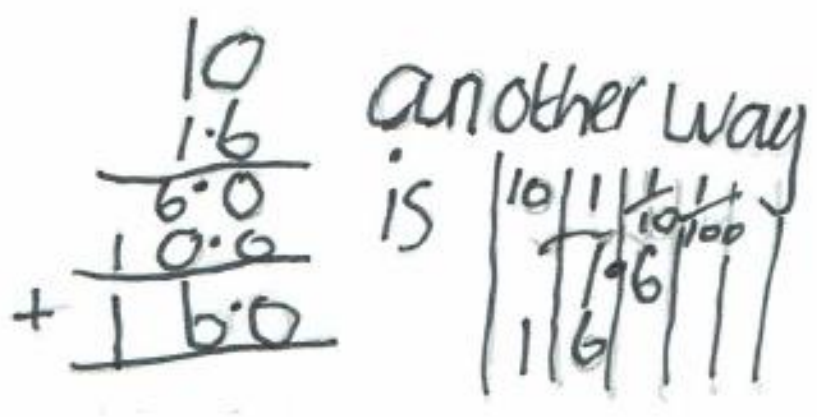

Figure 6. Sample from Ollie

Of the 530 students in the sample, only 49 (9.2\%) of them provided a conceptual response to at least one of the explanation questions. There were 19 Year 5 students and 30 Year 6 students who did so. As noted earlier only five students responded in a conceptual way to all four explanation questions. As well, 23 students responded conceptually to one question, 14 did so for two questions, and seven did so for three questions. It is unclear as to why a number of students were able to give conceptual responses to one or more questions but not to the others. Perhaps they did not see that all four questions were essentially about the same concept, that is, that when a number is multiplied or divided by a power of ten, its digits move a place for each power of ten. It might also be that some students saw multiplication as requiring them to 'add a zero' but that division was different and the digits moved a place (as did William - see Figure 4).

The important point to note here is that it appears that many students did not see or understand the connection between multiplication and division and that the two processes have an inverse relationship and effectively describe the same multiplicative situation about equal groups. This 'connectedness of thinking' was described earlier in the paper as being of critical importance in developing a conceptual understanding of multiplicative ideas.

\section{CONCLUSION}

The research question for this study asked: "To what extent do children of 10 and 11 years of age understand what happens to digit values when numbers are multiplied and divided by powers of ten?" Curriculum documents around the world expect that students at this age are capable of a conceptual understanding of multiplication by powers of ten, yet the results gained in this study indicates they are not doing so in numbers which could be considered appropriate. That $9.2 \%$ of the students in this study were able to demonstrate a conceptual understanding shows that it is not beyond a reasonable expectation, the fact that the number was so small is of concern. A further concern is that only five students from a sample of 530 could consistently demonstrate conceptual understanding. Most of the students who responded to the 'explanation questions' did so using a 'pseudo-procedure', saying that they 'added a zero' or 'moved the decimal point'. It is also surprising that, for two of the four questions $(16 \times 10)$, less than half of the students calculated a correct answer. Given that the sample consisted of students from three countries, it is reasonable to assume that the level of understanding demonstrated is reasonably typical across English speaking countries.

Some students gave a conceptual explanation (the movement of the digit) for multiplication questions, and a procedural response for division questions and vice versa. This inconsistency suggests that some students may not see multiplication and division as being the inverse of one another, but that they represent different situations and therefore need to be described differently. Some students talked about digit movement but described it through the process of adding a zero. This idea of adding a zero indicates a developing level of understanding only if the use of 'adding a zero' is a shortcut method of describing the job of the zero as a place holder, instead of a 'pseudo-procedural 'trick' to answering the question.

\section{RECOMMENDATIONS}

There are some clear implications for teaching. First, multiplication and division with powers of ten needs to be taught conceptually with explicit teaching about the movement of digits across places. The responses from student participants in this study seem to suggest that some teachers have actually taught the concept in that way and that this piece of Specialised Content Knowledge (SCK) is present in some of the teaching 
community, but it is not sufficiently widespread. Teaching should be done in association with a place value chart drawing on the base ten property of place value (see the theoretical framework in Figure 1 on page 3 ). The specific language of 'ten times as many' when a number is multiplied and 'ten times fewer' when a number is divided also needs to be explicitly taught. Focus questions are important here and need to be asked at key points. For instance, as a student moves a number one place on the place value chart, a question needs to be asked - "How many times as many has the number become"?

Second, multiplication and division should be taught simultaneously so that students can understand that they are the inverse of one another. Again, this can be done using the base ten property of place value and a place value chart with sliding numbers. Focus questions are important here as well and include, "What do I need to do to divide this number by ten?" and "What have I done to this number by moving it one ... two ... three ... places to the left?"

Third, the teaching of 'rules' and 'pseudo-procedures' such as 'adding a zero', 'crossing out a zero', and 'moving the decimal point' should be avoided, primarily because they are mathematically incorrect. Students need to be taught explicitly that the decimal point never moves and that its purpose is to separate whole numbers and parts of whole numbers. Teaching rules such as 'add a zero' is fraught with danger as students will invariably be frustrated when they use it to calculate answers to questions such as $3.6 \times 10$ - they will add a zero, obtain an answer of 3.60, and not understand why it is wrong.

To conclude, this paper advocates that, to be sustainable, the teaching of mathematics must be conceptual in nature and not based on 'pseudo-procedures' or 'rules without reasons'. The evidence presented here seems to support that call.

\section{Disclosure statement}

No potential conflict of interest was reported by the authors.

\section{Notes on contributors}

Chris Hurst - School of Education, Curtin University, Australia.

Derek Hurrell - University of Notre Dame Australia, Australia.

\section{REFERENCES}

Alcock, L., Ansari, D., Batechelor, S., Bison, M., De Smedt, B., Gilmore, C., ... Weber, K. (2016). Challenges in mathematical cognition: A collaboratively-derived research agenda. Journal of Numerical Cognition, 2(1), 20-41. https://doi.org/10.5964/jnc.v2i1.10

Anthony, G., \& Walshaw, M. (2002). Swaps and switches: Students' understandings of commutativity. In B. Barton, K. C. Irwin, M. Pfannkuch, \& M. O. J. Thomas (Eds.). Mathematics Education in the South Pacific (Proceedings of the 25th annual conference of the Mathematics Education Research Group of Australasia, Auckland) pp. 91-99. Sydney: MERGA. Retrieved from https://merga.net.au/Public/Publications/Annual_Conference_Proceedings/2002_MERGA_CP.aspx

Anthony, G., \& Walshaw, M. (2009). Effective pedagogy in mathematics. Belley, France: United Nations Educational, Scientific and Cultural Organisation. Retrieved from http://www.ibe.unesco.org/publications.htm

Australian Curriculum, Assessment and Reporting Authority (ACARA) (2020). Australian curriculum mathematics - Version 8.3. Retrieved from http://www.australiancurriculum.edu.au/Mathematics/ Curriculum/F-10

Baroody, A. J., Feil, Y., \& Johnson, A. R. (2007). An alternative reconceptualization of procedural and conceptual knowledge. Journal for Research in Mathematics Education, 38, 115-131. Retrieved from https://www-jstor-org.dbgw.lis.curtin.edu.au/stable/pdf/30034952.pdf

Canobi, K. H. (2009). Concept-procedure interactions in children's addition and subtraction. Journal of Experimental Child Psychology, 102, 131-149. https://doi.org/10.1016/j.jecp.2008.07.008 
Clements, D., \& Sarama, J. (2019) From Children's Thinking to Curriculum to Professional Development to Scale: Research Impacting Early Maths Practice. In G. Hine, S. Blackley, \& A. Cooke (Eds.). Mathematics Education Research: Impacting Practice (Proceedings of the 42nd annual conference of the Mathematics Education Research Group of Australasia) pp. 36-48. Perth: MERGA. Retrieved from https://merga.net.au/Public/Publications/Annual_Conference_Proceedings/2019-MERGA-conferenceproceedings.aspx

diSessa, A. A., Gillespie, N. M., \& Esterly, J. B. (2004). Coherence versus fragmentation in the development of the concept of force. Cognitive Science, 28, 843-900. https://doi.org/10.1207/s15516709cog2806_1

Downton, A., Russo, J., \& Hopkins, S. (2019). The case of disappearing and reappearing zeros: A disconnection between procedural knowledge and conceptual understanding. In G. Hine, S. Blackley, \& A. Cooke (Eds.). Mathematics Education Research: Impacting Practice (Proceedings of the 42nd annual conference of the Mathematics Education Research Group of Australasia) pp. 236-243. Perth: MERGA. Retrieved from https://merga.net.au/Public/Publications/Annual_Conference_Proceedings/2019MERGA-conference-proceedings.aspx

Givvin, K. B., Stigler, J. W., \& Thompson, B. J. (2011). What community college developmental mathematics students understand about mathematics, Part II: The interviews. The MathAMATYC Educator, 2(3), 4-18. Retrieved from https://doi.org/10.1080/00461520.2012.667065

Hiebert, J. (1986). Conceptual and procedural knowledge: The case of mathematics. Hillsdale, N.J.: Erlbaum.

Hiebert, J. (1999). Relationships between research and the NCTM standards. Journal for Research in Mathematics Education, 30(1), 3-19. https://doi.org/10.2307/749627

Hiebert, J., \& Grouws, D. A. (2007). The effects of classroom mathematics teaching on students' learning. In F. K. Lester (Ed.), Second handbook of research on mathematics teaching and learning (pp. 371-404). Charlotte, NC: Information Age.

Hiebert, J., \& Lefevre, P. (1986). Conceptual and procedural knowledge in mathematics: An introductory analysis. In J. Hiebert (Ed.), Conceptual and procedural knowledge: The case of mathematics (pp. 1-27). Hillsdale, NJ: Erlbaum.

Hurst, C. (2017). Children have the capacity to think multiplicatively, as long as . . European Journal of STEM Education, 2(3), 1-14. https://doi.org/10.20897/ejsteme/78169

Hurst, C. (2018). A tale of two kiddies: A Dickensian slant on multiplicative thinking. Australian Primary Mathematics Classroom, 23(1), 31-36. Retrieved from https://search-informit-comau.dbgw.lis.curtin.edu.au/documentSummary;dn=485064898800183;res=IELHSS

Miller, S. P., \& Hudson, P. J. (2007). Using evidence-based practices to build mathematics competence related to conceptual, procedural, and declarative knowledge. Learning Disabilities Research and Practice, 22(1), 47-57. Retrieved from https:///doi.org/10.1111/j.1540-5826.2007.00230.x

National Governors Association Center for Best Practices, Council of Chief State School Officers (NGA Center). (2010). Common core state standards for mathematics. Retrieved from http://www.corestandards.org/the-standards

Pesek, D. D., \& Kirshner, D., (2000). Interference of instrumental instruction in subsequent relational learning. Journal for Research in Mathematics Education, 31, 524-540. https://doi.org/10.2307/749885

Puchner, L., Taylor, A., O’Donnell, B., \& Fick, K. (2010). Teacher learning and mathematics manipulatives: A collective case study about teacher use of manipulatives in elementary and middle school mathematics lessons. School Science and Mathematics, 108(7), 313-325. Retrieved from https://doi.org/10.1111/j.1949-8594.2008.tb17844.x

Resnick, L. B., \& Ford, W. W. (1981). The psychology of mathematics for instruction. Hillsdale: Erlbaum.

Richland, L. E., Stigler, J. W., \& Holyoak, K. J. (2012). Teaching the Conceptual Structure of Mathematics, Educational Psychologist 47(3), 189-203. https://doi.org/10.1080/00461520.2012.667065

Rittle-Johnson, B. (2017). Developing mathematics knowledge. Child Development Perspectives, 11(3), 184190. https://doi.org/10.1111/cdep.12229

Rittle-Johnson, B. Schneider, M., \& Star, J. (2015). Not a one-way street: Bi-directional relations between procedural and conceptual knowledge of mathematics. Educational Psychology Review, 27. https://doi.org/10.1007/s10648-015-9302-x 
Rittle-Johnson, B., \& Koedinger, K. R. (2009). Iterating between lessons concepts and procedures can improve mathematics knowledge. British Journal of Educational Psychology, 79, 483-500. Retrieved from https://doi.org/10.1348/000709908X398106

Rittle-Johnson, B., \& Schneider, M. (2015). Developing conceptual and procedural knowledge in mathematics. In R. Cohen Kadosh \& A. Dowker (Eds.), Oxford handbook of numerical cognition (pp. 1102-1118). Oxford, UK: Oxford University Press. https://doi.org/10.1093/oxfordhb/9780199642342.013.014

Rittle-Johnson, B., Fyfe, A.M., \& Loehr, E.R. (2016). Improving Conceptual and Procedural Knowledge: The Impact of Instructional Content Within A Mathematics Lesson. British Journal of Educational Psychology, 86(4), 576-591. https://doi.org/10.1111/bjep.12124

Rittle-Johnson, B., Siegler, R. S., \& Alibali, M. W. (2001). Developing conceptual understanding and procedural skill in mathematics: An iterative process. Journal of Educational Psychology, 93, 346-362. https://doi.org/10.1037/0022-0663.93.2.346

Ross, S. (2002). Place value: Problem solving and written assessment. Teaching Children Mathematics, March 2002, 419-423. Retrieved from https://search-proquest-com.dbgw.lis.curtin.edu.au/docview/214137991/ abstract/14585DF896874B80PQ/9?accountid=10382

Schneider, M., \& Stern, E. (2009). The Inverse Relation of Addition and Subtraction: A Knowledge Integration Perspective. Mathematical Thinking and Learning, 11, 92-101. Retrieved from: https://doi.org/10.1080/10986060802584012

Schneider, M., Rittle-Johnson, B., \& Star, J. R. (2011). Relations between conceptual knowledge, procedural knowledge, and procedural flexibility in two samples differing in prior knowledge. Developmental Psychology, 47(6), 1525-1538. https://doi.org/10.1037/a0024997

Siegler, R. S., Duncan, G. J., Davis-Kean, P. E., Duckworth, K., Claessens, A., Engel, M., Susperreguy, M. I., \& Chen, M. (2012). Early Predictors of High School Mathematics Achievement. Psychological Science, 23(7), 691-697. https://doi.org/10.1177/0956797612440101

Siemon, D., Bleckly, J., \& Neal, D. (2012). Working with the Big Ideas in Number and the Australian Curriculum: Mathematics. In B. Atweh, M. Goos, R. Jorgensen, \& D. Siemon (Eds.), Engaging the Australian National Curriculum: Mathematics - Perspectives from the Field (pp. 18-45). Online Publication: Mathematics Education Research Group of Australasia. Retrieved from https://merga.net. au/Public/Public/Publications/Engaging_the_Australian_curriculum_mathematics_book.aspx

Siemon, D., Breed, M., Dole, S., Izard, J., \& Virgona, J. (2006). Scaffolding Numeracy in the Middle Years Project Findings, Materials, and Resources (Final Report), Victorian Department of Education and Training and the Tasmanian Department of Education. Retrieved from http://www.eduweb.vic.gov.au/edulibrary/public/teachlearn/student/snmy.ppt

Skemp, R. (1976). Relational and instrumental understanding. Mathematics Teaching in the Middle School, 12(2), 88-95. Retrieved from http://www.jstor.org/stable/41182357

Sowder, J. T. (1998). What are the "math wars" in California all about? Reasons and perspectives. Retrieved from http://staff.tarleton.edu/brawner/coursefiles/579/Math\%20Wars\%20in\%20California.pdf

Stigler, J. W., Givvin, K. B., \& Thompson, B. J. (2010). What community college developmental mathematics students understand about mathemDDatics. Mathematics Teacher, 1(3), 4-16. Retrieved from https://www.researchgate.net/publication/260908914

Warren, E., \& English, L. (2000). Primary school children's knowledge of arithmetic structure. In J. Bana \& A. Chapman (Eds.), Mathematics Education beyond 2000 (Proceedings of 23rd annual conference of the Mathematics Education Research Group of Australasia, Fremantle). pp. 624-631. Sydney: MERGA. Retrieved from https://merga.net.au/Public/Publications/Annual_Conference_Proceedings/ 2000_MERGA_CP.aspx 